\title{
EL BORDADO CAÑARI: SÍMBOLO DE IDENTIDAD PRECOLOMBINO E INSTRUMENTO DE REBELDÍA DURANTE LA CONQUISTA ESPAÑOLA
}

\section{CAÑARY EMBROIDERY: SYMBOL OF PRE-COLUMBINE IDENTITY AND INSTRUMENT OF REBELLION DURING THE SPANISH CONQUEST}

\begin{abstract}
Elisa Guillén Serrano
Diseñadora de Textil y Moda, de nacionalidad ecuatoriana. Graduada en la Universidad del Azuay en el año 2014. Actualmente se encuentra culminando la Maestría en Diseño, Desarrollo e Innovación de Indumentaria de Moda impartida por la Universidad Técnica de Ambato. Se desempeña como catedrática en la Universidad del Azuay, con experiencia en capacitaciones a artesanos del sector textil, enmarcadas en proyectos de vinculación con la colectividad.
\end{abstract}

eguillen@uazuay.edu.ec

Fecha de recepción: 3 de abril, 2016 / Aceptación: 30 de junio, 2016. 


\section{Resumen}

El bordado textil en las prendas de la cultura cañari fue un importante símbolo en la construcción y preservación de su ideología. Durante la época precolombina esta técnica ancestral fue mucho más que un ornamento y constituyó una trascendental práctica cultural, con significativa expresión artística y representación simbólica, arraigada en la cosmovisión de su pueblo, tanto que durante la etapa de colonización española se utilizó como una forma de rebeldía ante la corona. Por eso, la práctica del bordado, que se extendió durante diferentes periodos, aportó a la construcción de la identidad local.

Palabras clave: ancestral, cultura, cosmovisión, tradición, vestimenta.

\section{Abstract}

Textile embroidery in Cañari clothing was an important symbol in the construction and preservation of their ideology. During the pre-Columbine period this ancestral technique was more than an ornament. It constituted a transcendent cultural practice with significant artistic expression and symbolic representation rooted in the cosmovision of their people. So much so, that during the Spanish colonization period it was used as a form of rebellion against the crown which resulted in the extension of this activity during different periods and the construction of Cañari identity.

Keywords: ancestral culture, clothing, cosmovision, tradition. 


\section{Introducción}

El Ecuador es cuna de una variedad de grupos, un país pluricultural porque en él coexisten de forma armoniosa y respetuosa varias culturas, cada una con sus propios rasgos identitarios tales como costumbres, tradiciones, vestimenta, lengua, ideología, etc. Cada uno de estos grupos cuenta por medio de sus símbolos y signos la historia de su propia identidad. Uno de los rasgos identitarios de una cultura es su vestimenta que, además de sus funciones básicas de cobertura y protección, constituye un importante elemento de ornamentación, expresión y comunicación.

En medio de un mundo orientado a la homogeneización por la influencia de la globalización, el desarrollo de las comunicaciones y la tecnología, las culturas autóctonas se ven amenazadas hasta el punto de que podrían desaparecer, por lo que es preciso que los diseñadores puedan aportar al fortalecimiento de la conciencia colectiva y resalten la importancia de las técnicas ancestrales y sus diferentes connotaciones culturales a través del tiempo. En la presente investigación se lleva a cabo un análisis de la técnica del bordado y los significados en la vestimenta cañari durante el período precolombino, y se la compara con los bordados propios de la época de la colonia.

\section{Reflexiones y miradas del contexto}

Vivimos en un mundo que cambia constantemente. De forma general, se pueden apreciar tres etapas de cambio que ha enfrentado: la conquista española, la revolución industrial y la revolución de la tecnología y las telecomunicaciones. Estos fenómenos han influenciado en nuestro modo de vivir, de relacionarnos y comunicarnos, pues, como comenta Bauman (2004): "Quien controla las emisiones de onda controla el mundo en el que vivimos, decide su forma y sus contenidos" (p.165). La información se transmite de manera acelerada por un sinnúmero de vías y nos propone muchos caminos para elegir; esto se ve representado, metafóricamente hablando en palabras de Bauman, como la modernidad líquida. Dicha teoría sostiene que la identidad del individuo funciona de la misma manera que un líquido, es decir, cambia constantemente y presenta reacciones flexibles ante las diversas situaciones que enfrenta el ser humano al intentar integrarse a una sociedad global y homogenizada. Según esta perspectiva, las personas están constantemente cambiándose de máscaras para lograr adaptarse a diferentes contextos. En este fenómeno se evidencia la pérdida de la identidad. "El aspecto más notable del acto de desaparición de las antiguas seguridades es la nueva fragilidad de los vínculos humanos" (Bauman, 2004, p.181); el deseo de sumergirnos en el mundo globalizado nos lleva a buscar el éxito individual, a olvidarnos de la tradición, de la vida en comunidad, de lo sólido, para seguir el paso acelerado y competitivo de un mundo dominado por el mimetismo, el consumismo y lo efímero, donde la novedad pronto se vuelve obsoleta.

Otra causa de la pérdida de la identidad es la migración, que se vincula con lo analizado anteriormente. El individuo, en el intento de mejorar su calidad de vida, se moviliza a países más desarrollados en búsqueda de oportunidades de trabajo y en medio de este proceso se ve obligado a adaptarse a un nuevo contexto y a transformar su cultura adoptando elementos ajenos, vive así un proceso de aculturación que repercute en la gente. De esta manera surge una hibridación de prácticas culturales, se van modificando e incluso olvidando las tradiciones, lo que trae como consecuencia el debilitamiento de la identidad.

Afortunadamente mediante el análisis de esta realidad, nace una tendencia contrapuesta pues, 
Los seres humanos no se consideran casi nunca entes aislados y autónomos, sino integrantes de una unidad mayor en la que encuentra sentido su vida. Si los cambios amenazan la subsistencia o fortaleza de esa unidad mayor, se genera y refuerza la tendencia a preservarla mediante la oposición al cambio (Malo, 2006, p.44).

Esta corriente busca reforzar la identidad anteponiendo lo local a lo global, el ser humano quiere retomar lo que lo hacía diferente. Este afán se evidencia ya incluso en las políticas de los gobiernos, como en el caso de nuestro país en el que existe un interés por rescatar los saberes ancestrales. Por esta razón, el presente estudio está orientado a analizar una de las expresiones más antiguas del pueblo cañari, la técnica del bordado, para entender cómo constituyó una práctica cultural de carácter simbólico que reflejó la ideología de un grupo y, además, funcionó como ornamento y expresión artística cultural. Dar a conocer la importancia del bordado, que estuvo latente desde tiempos precolombinos y de una u otra manera continuó vigente aún después de dos conquistas, contribuirá a alimentar el ánimo de lucha para la preservación de las prácticas culturales ancestrales y a revalorizar su carácter como símbolo de la identidad. Vale aclarar que la identidad cultural puede ser comprendida "como el conjunto de rasgos que dan el tono peculiar y característico a una cultura estructurándola como una unidad diferente" (Malo, 2006, p.42). Con ello también podemos hablar del principio de otredad, podemos reconocernos como parte de una misma cultura solo en la medida en la que nos diferenciamos de los demás.

Hemos elegido analizar este tópico desde el enfoque de la historia cultural debido a que para entender la técnica del bordado y sus diferentes dimensiones dentro de la cultura cañari es menester analizar la ideología de este pueblo, estudiar su simbolismo y analizar las distintas interpretaciones sobre el bordado dentro de su contexto social, tanto en el período precolombino como cuando llegan los incas y ocurre la conquista española. Analizar esta problemática desde la historia cultural implica atender la cultura popular, ya que se considera que la pintura, escultura y demás artes de la alta cultura solamente están enfocados dentro de la realidad de la burguesía occidental, mientras que existen diversas expresiones como la música popular, la artesanía y, por supuesto, las técnicas textiles que forman parte de los rasgos que emergen de los pueblos y que nos ayudan a comprender su ideología.

El origen del pueblo cañari data del año 500 d. C. Su origen se explica en dos leyendas. La primera habla sobre una inundación en la que se ahogaron todos los habitantes de Cañaribamba con excepción de dos hermanos que se resguardaron en la cumbre de un monte; allí fueron alimentados por unas guacamayas con cara de mujer. Uno de los hermanos se casó con una de las guacamayas y juntos se convirtieron en los progenitores del pueblo cañari. El segundo mito hace alusión a la laguna de Culebrillas; el mito asegura que una serpiente puso allí dos huevos de los que salieron un hombre y una mujer y de estos descendieron los cañaris, por lo que la laguna era considerada un lugar sagrado al que se lanzaban múltiples ofrendas.

Sobre la vestimenta del pueblo, se sabe que durante las fiestas los cañaris llevaban:

\section{Camisetas con chaperías de plata y unas huaracas con botones de plata y plumas de diversos colores de guacamayas y unos alzacuellos de plumas, que en algunas par- tes llaman Huacras y en otras Tamta, y todos estos ornamentos los guardan para este efecto (Arriaga, 1920[1621], p.31).}

A partir de esta descripción podemos inferir que las prendas llevaban adornos bordados con una connotación simbólica; las plumas de las guacamayas, por ejemplo, se relacionaban con el origen de su pueblo. Pero cabe resaltar que los cañaris creían en la magia y eran una cultura muy supersticiosa, por lo que estos adornos bien pueden haber constituido incluso una especie de amuletos.

Las fiestas que celebraban, de la misma 
manera que los temas bélicos, se practicaron en grupo, pues si bien los cañaris se dividieron en señoríos en los que un cacique específico se encargaba de la organización, tanto en momentos de celebración como en los de angustia, el pueblo se unía para tomar decisiones en conjunto. Ciertamente, la dualidad andina -cada señorío se complementaba con otro- fue un elemento de su filosofía de praxis. Aquí se evidencia claramente lo que había postulado Maffesoli (1990), en su libro El tiempo de las Tribus, la unión que caracterizaba a las tribus arcaicas y cómo esta unión ha influenciado en la aparición de las Ilamadas tribus urbanas, y cómo el pensamiento popular de América Latina se fue desvaneciendo por la imposición del llamado "progreso".

Las tribus actuales nacen precisamente de la masificación. Los individuos se sienten desorientados, confundidos y sin identidad, en un mundo superficial donde el éxito personal y el consumo son la meta, por esta razón se unen a un grupo en busca de pertenencia y forman vínculos y relaciones de solidaridad con los demás miembros. Si bien el estudio de Maffesoli (1990) se centra en el análisis de las tribus urbanas actuales, este sistema se ve inspirado por las tribus arcaicas por lo que en la presente investigación se quiere resaltar la importancia que tiene la autoafirmación de la identidad de los individuos y la necesidad de pertenecer a un grupo para compartir, relacionarse y diferenciarse de los demás. "Al mismo tiempo, como el proyecto, el futuro, el ideal ya no sirven de argamasa a la sociedad, el ritual, al confortar el sentimiento de pertenencia, puede jugar este papel y permitir, así, la existencia de los grupos" (Maffesoli, 1990, p.169). El autor señala además del ritual, a las ceremonias y demás expresiones simbólicas como prácticas culturales de relevancia en este proceso de construcción de la identidad, porque dan sentido a la existencia de las personas y los grupos.

Esto mismo ocurre con el caso del bordado de la cultura cañari. Forma parte de sus rituales, pues está presente en la vestimenta y de esa forma permite identificar a los que lo llevan como miembros de un mismo grupo.
Como referencia histórica se conoce que en el Ecuador, ya desde la época preincaica, los pueblos Cañaris conocían el hilado del algodón, y se han encontrado agujas en cobre y hueso, lo que da indicios de un conocimiento y uso del hilo no solamente para tejer, sino para coser y ornamentar con hilos (Malo, 2008, p.195).

En esta cita nos encontramos con otra connotación del bordado: tomó importancia como ornamento, los cañaris lo utilizaban para engalanar sus atuendos. En efecto, sostenía Darwin, "Los vestidos surgieron primeramente con un fin ornamental y no para producir una sensación de calor" (citado por Squicciarino, 1998, p.47). Esta función ornamental entiende a los humanos como seres "desprovistos" que se ven obligados a refugiarse en la creatividad del "homo ludens" reflejándose en un fenómeno de juego con el cuerpo, que trae como resultado la ornamentación mediante ciertos elementos del vestido. Asimismo, el bordado pasa a ser un instrumento de expresión artística ya que en medio de ese juego "el afán de propiciar relaciones positivas y amigables con lo sobrenatural, afina las facultades y los sentimientos del artista popular y lo conducen a realizaciones intensas y saturadas de sentimiento" (Malo, 2006, p.193). El hecho de que los cañaris trataran de representar el mundo que los rodeaba, la mitología y las leyendas de su pueblo por medio de hebras y agujas convierte a esta práctica cultural en una expresión artística en la que, lo explica Malo (2006), la gratificación psicológica proviene de la capacidad para expresar con mayor autenticidad las vivencias del grupo. Esta conexión del bordado con las vivencias colectivas lo convierte en una expresión que se puede entender desde el arte popular y no desde las artes mayores occidentales, ya que en las últimas, la gratificación del artista es únicamente el reconocimiento personal.

Algo similar a lo sucedido en la época anterior tuvo lugar durante la conquista inca, pues su forma de invasión fue muy distinta a la de los españoles. Los cañaris no fueron un blanco fácil ya que 
fueron grandes guerreros, no obstante, tras algunas batallas ofrecieron obediencia y sumisión al imperio inca hacia el año 1470 d. C. Huayna Cápac construyó varios templos de adoración a su deidad el sol, Inti, así como a la luna o Quilla; sin embargo, respetó las tradiciones cañaris y esto se puede evidenciar en la laguna de Culebrillas que constituía un adoratorio cañari y al que los incas convirtieron en un tambo con construcciones muy adornadas y suntuosas. Lo mismo sucedió con la vestimenta. De esto nos hablan Caivano y López (2006), describen que la indumentaria precolombina marcaba estatus social y que las camisetas de los reyes, también conocidas como uncus, llevaban bordados de oro y plata y adornos de plumas en colores muy llamativos a diferencia de los trajes de los seres humanos comunes que eran confeccionados en fibras naturales.

Según esta descripción. los cambios en la vestimenta no fueron drásticos ni impositivos, sino que se tomaron elementos de ambos pueblos, así fue que los cañaris adoptaron las figuras bordadas que formaban parte de los uncus y recibían el nombre de tocapu (figura 1.) Estas tenían formas geométricas, zoomorfas, etc. que, según se cree, fueron un tipo de escritura y representaban la cosmovisión del pueblo, pues los incas veían el mundo en tres dimensiones: la primera el Hanan Pacha o mundo de arriba donde se identificaban el sol, la luna y los astros; el segundo era el Hurin o Kay Pacha que viene a ser el mundo de aquí, donde habitaban los seres vivos, y por último en el Uku Pacha o mundo de abajo, donde se encontraban las almas de las personas.

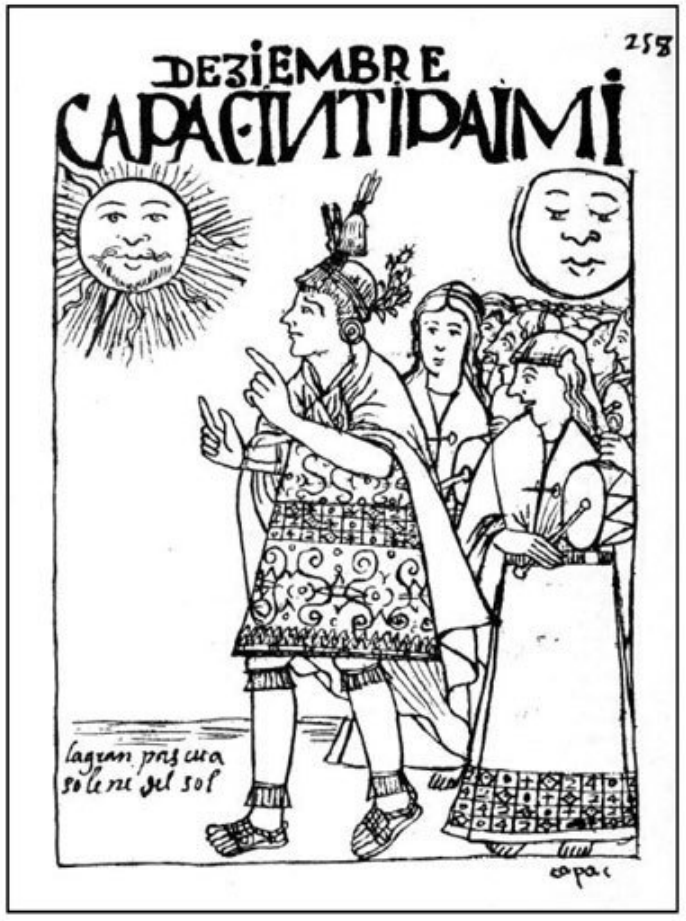

Figura 1. Vestimenta Inca en el Capac Inti Raymi (Guamán Poma, 1980[1613]).

Además, estos textiles eran ofrecidos como pago de tributos, para sellar pactos, terminar guerras, para sacrificios ceremoniales, así como también se colocaban en los ajuares de novias y difuntos, por lo que se puede ver que el bordado en la vestimenta era un símbolo de poder y distinción dentro de la ideología de esta cultura.

Posteriormente ocurrió una guerra civil entre los hijos de Huayna Cápac. En este conflicto los cañaris tomaron partido por Huáscar, pero perdieron la batalla, por esta razón se aliaron a los españoles en la captura de Atahualpa durante la conquista hacia 1533. Así los cañaris aceptaron el dominio español y se sometieron al proceso de evangelización. Como consecuencia de la conquista comienza el llamado mestizaje.

Este fenómeno tuvo lugar así mismo en la indumentario, paralelo al mestizaje se dio el cultural. "El convivir diario de estos grupos permearon sus usos y costumbres -unos más que otros-, 
combinándose elementos culinarios, religiones, idiomas, tradiciones, fiestas, vestuarios y muchos otros de la cultura material e inmaterial (Arteaga, 2012, p.132).

La transformación de la indumentaria en el Azuay y Cañar, sin embargo, fue distinta de la de la Sierra norte y centro donde se encontraban los obrajes en los que los indígenas eran obligados a trabajar en condiciones denigrantes para pagar el tributo a la corona. Como lo cuenta Burgos (2003), la población cañari se vio muy reducida hacia el inicio de la época de la colonia debido a la guerra civil entre Huáscar y Atahualpa, así como a la alta tasa de mortalidad que se generó a partir de las epidemias que trajeron consigo los españoles, por lo que no quedaban muchos "mitayos" para ponerlos a trabajar en las minas de plata de la región. Este fenómeno causó la inmigración de indígenas de otras provincias que, huyendo de las mitas (un sistema de trabajo indígena en condiciones de esclavitud que se realizaba para pagar el tributo a la corona española) y demás sistemas infrahumanos, acudían a la Sierra sur para pagar un tributo más bajo, de ese modo, adoptaron las costumbres cañaris.

Durante esta etapa, "según el Derecho español, los habitantes de sus colonias debían usar diferentes tipos de trajes, acorde con su grupo étnico; a estas disposiciones debían sumarse otras, locales, que iban a caracterizar de buena manera a urbes y pueblos" (Arteaga, 2012, p.134). Esta imposición emergió para distinguir entre indios y mestizos y con ello determinar el pago de tributos.

En Cañar y Azuay, quizá como en ningún corregimiento de la Sierra, los actores sociales recurrieron a suprimir uno de los rasgos más evidentes -después de la raza- que los delataba como "indios". Este rasgo fue la vestimenta, junto a la acción judicial de declararse (real o falsamente) hijo lejano de un padre mestizo (Burgos, 2003, p.24).

En consecuencia, estos indígenas optaron por un sistema de camuflaje, ya que hacia esa época la diferencia en el color de la piel entre indios y mestizos no estaba muy definida. Aquellos que en los registros constaban únicamente como hijos de madre india fácilmente adoptaron dos piezas de vestuario mestizo, como resultado surgió una hibridación en la vestimenta que los identificaba como cholos. "Hacia el siglo XVII, muchas mujeres nativas de la parroquia y la periferia de la ciudad de Cuenca vistieron combinando con piezas de ropa de uso ancestral y de chola" (Money, 2012, p.187). Se puede notar así que para este fin no abandonaron del todo su vestimenta tradicional y que los bordados representaban, al igual que durante el período precolombino, un símbolo de poder. En efecto,

Para asistir a las celebraciones cívicas y los santos rituales de la Iglesia, la vestimenta de la "india mestiza en hábito de india", para fines del siglo XVII, muestra también su poder económico. Su blusa era de manga corta y ajustada hasta la cintura, con una pechera bordada con seda de color carmesí e hilos de oro y lentejuelas (Money, 2012, p.188).

Se ha hablado ya de la india mestiza en hábito de india o chola, pero ¿qué sucedió con los indígenas que no pasaron por este mestizaje y continuaron utilizando su vestimenta étnica que los marcaba como "mitayos"? En 1781 sucedió una sublevación general indígena, que luchó contra el sistema hegemónico de la colonia española y contra la disposición de la corona, la ley que indicaba que los indios debían adoptar la misma vestimenta que la gente popular de España, "los grupos étnicos de los ayllus fueron obligados a usar pollera de bayeta de tierra, reboso de castilla, jubón de bayeta de la tierra, sombrero de oveja y otros tipos de tocados bordados." (Money, 2012: 188) Por eso, a pesar de estas disposiciones, los indígenas continuaron utilizando muchas de sus prendas, ornamentaciones y colores prehispánicos como símbolo de resistencia. 
Se podría analizar este fenómeno desde el enfoque de Foucault (1989) que habla sobre las discontinuidades o rupturas. En este momento toma relevancia el concepto de invención, pues estas rupturas se generan por la imposición del poder:

Pero este sometimiento no se obtiene por los únicos instrumentos ya sean de violencia, ya de la ideología, puede ser muy bien directo, físico, emplear la fuerza contra la fuerza, obrar sobre elementos materiales, y a pesar de todo esto no ser violento; puede ser calculado, organizado, técnicamente reflexivo, puede ser sutil, sin hacer uso ni de las armas ni del terror y, sin embargo, permanecer dentro del orden físico (p.196).

Podemos comparar este pensamiento con la imposición de poder por parte de la colonia española que, en este caso, utilizó a la vestimenta como estrategia para alterar el orden social de esa época mediante disposiciones que dieron lugar a una ruptura del traje prehispánico; la hibridación de los dos tipos de indumentaria trajo como consecuencia un nuevo vestuario. Además, el aporte de Foucault a la historia cultural habla acerca de "...su estudio acerca del control del pensamiento y las formas de exclusión de los discursos amenazadores para el régimen" (Hernández, 2010, p.419), ya que la intención de una institución, en este caso de la corona española, era eliminar el sentido de pertenencia e identidad que los indígenas creaban a través de su vestuario para convertirlos en "cuerpos dóciles" que puedan ser fácilmente dominados. Aun así, podemos notar cómo la ideología del pueblo cañari y de otros más fue tan fuerte que no permitió esta hegemonía; actuaron como miembros de un grupo tribal "en donde compartir una costumbre, una ideología 0 un ideal les permite protegerse de las imposiciones (racionales 0 autoritarias), vengan de donde vengan (Maffesoli, 1990, p.169). En efecto, los cañaris continuaron utilizando elementos iconográficos propios en sus bordados y tejidos preservando esta técnica ancestral como una práctica cultural que los unía como grupo y los ayudaba a fortalecer su identidad.

\section{Conclusiones}

Como conclusión se puede afirmar que el bordado, como parte de la vestimenta, constituye un importante rasgo cultural de un pueblo porque aporta a la construcción de su identidad. Durante el periodo precolombino este elemento cultural actuó como símbolo ornamental y como una expresión artística que reflejaba al mundo que los rodeaba, junto con el pensamiento mitológico y mágico. Se puede ver, asimismo, que durante el período incaico la tradición continuó vigente de manera armónica y no sufrió un proceso de exterminio, sino que, por el contrario, los incas respetaron la práctica cultural de los cañaris y la fusionaron con sus conocimientos, por lo que el bordado en la vestimenta pasó a constituir un símbolo de su cosmovisión e ideología, que contaba con una importante significación política, religiosa y social al ofrecerse como tributo 0 intercambio, al utilizarse en las ceremonias y al distinguir niveles dentro de la sociedad.

Durante la conquista española, por su parte, se evidenciaron dos fenómenos en la vestimenta: el primero constituyó un sistema de camuflaje para evitar las crueldades del nuevo régimen y el segundo fue el uso de la vestimenta como una estrategia de rebelión al continuar utilizando prendas, iconografías y técnicas ancestrales con las que los cañaris fortalecieron su conciencia como grupo y mostraron la necesidad de que sus prácticas culturales perduren en el tiempo como símbolo de su identidad. De esta manera, en este estudio hemos dado a conocer los distintos significados que adquirió el bordado de la vestimenta cañari tanto en la época precolombina como en la colonia española y hemos confirmado que esta técnica ancestral contribuyó a la construcción y preservación de la identidad de este pueblo. Sin embargo, a partir de este análisis surgen 
nuevas incógnitas: ¿es posible que, al igual que los cañaris, podamos preservar estas técnicas ancestrales y protegerlas de los cambios que se están presentando a partir de fenómenos actuales como la globalización?, ¿qué puede hacer la sociedad de la contemporaneidad para preservar estos rasgos que forman parte de la identidad de los grupos culturales de nuestro país en medio de un mundo que camina hacia la homogenización?

Esperamos que esta investigación sirva para reflexionar y tomar conciencia de la importancia de las técnicas ancestrales como instrumentos para reforzar la identidad. También esperamos que se analice este tópico desde otras perspectivas como la de la sostenibilidad, ya que, por ejemplo, el bordado ancestral se realizaba a mano y no consumía luz eléctrica a diferencia de las máquinas bordadoras actuales, o bien se podría priorizar la importancia del grupo sobre el individuo, la forma de búsqueda del bienestar colectivo que se da en la práctica, al igual que lo hacían las tribus y grupos del pasado. Se espera que entender estas tradiciones ancestrales desde sus diferentes connotaciones, incentive a los diseñadores a aportar con sus conocimientos para presentar diversas estrategias y soluciones que permitan la supervivencia de estas prácticas culturales.

\section{Referencias bibliográficas}

Arteaga, D. (2012). Sobre las indumentarias en la Cuenca colonial como parte del mestizaje cultural. Cuenca: Revista Universidad Verdad de la Universidad del Azuay, 129-146.

Arriaga, P. (1920[1621]). Extirpación de la idolatría en el Perú. Lima: Imprenta y Librería San Martín.

Bauman, Z. (2004). La modernidad líquida (Mirta Rosenberg, trad.). Argentina: Fondo de Cultura Económica.

Burgos, H. (2003). La identidad del pueblo Cañari, de-construcción de una nación étnica. Quito: Ediciones Abya Yala.

Caivano, J. y López, M. (2006). Color: ciencia, artes, proyecto y enseñanza. Buenos Aires: Grupo argentino del color.

Foucault, M. (1989). El cuerpo político. En Croci, P. y Vitale, A. (Comp.). Los cuerpos dóciles. (pp. 194-199). Argentina: La marca editora.

Guamán Poma, F. (1980[1613]). Nueva Coronica y buen gobierno. Venezuela: Biblioteca Ayacucho.

Hernández, A. (2010). Reseña de "¿Qué es la historia cultural? De Peter Burke. Colombia: Instituto Colombiano de Antropología e Historia.

Maffesoli, M. (2004). El tiempo de las tribus (Daniel Gutiérrez Martínez, trad.) México: Siglo XXI editores.

Malo, G. (2006). Arte y cultura popular. Cuenca: CIDAP - Universidad del Azuay.

Malo, G. (2008). Cuenca ciudad artesanal. Cuenca: CIDAP.

Money, M. (2012) La mujer andina en el mestizaje: La chola cuencana y paceña en la construcción de la identidad (siglos XVII-XX). Revista del II encuentro nacional de historia de la provincia del Azuay, pp. 183-188.

Squicciarino, N. (1998). El vestido habla. (José Luis Aja Sánchez, trad.). Madrid: Ediciones Cátedra.

\section{Figuras}

Figura 1. Poma Guamán (1613). Vestimenta Inca en el Capac Inti Raymi. [Ilustración]. 
